\title{
Uncertainty and Immunity in Public Communications on Pandemics
}

\author{
Mark Davis
}

Abstract This chapter examines uncertainty in the expert advice on pandemics given to members of the general public. The chapter draws on research conducted in Australia and Scotland on public engagements with the 2009 influenza (swine flu) pandemic and discusses implications for communications on more recent infectious disease outbreaks, including Ebola and Zika. It shows how public health messages aim to achieve a workable balance of warning and reassurance and deflect problems of trust in experts and science. The chapter considers how uncertainties which prevail in pandemics reinforce the personalization of responses to pandemic risk, in ways that undermine the cooperation and collective action which are also needed to respond effectively to pandemics.

Keywords COVID-19 $\cdot \mathrm{HINl} \cdot 2009$ pandemic $\cdot$ Pandemic communication - Public response - Personalization - Immunity

M. Davis $(\square)$

School of Social Sciences, Monash University, Clayton, VIC, Australia e-mail: mark.davis@monash.edu

(C) The Author(s) 2019

K. Bjørkdahl and B. Carlsen (eds.), Pandemics, Publics, and Politics, https://doi.org/10.1007/978-981-13-2802-2_3 
Uncertainty is a central challenge for public communications on matters pandemic. Recent efforts to respond to outbreaks of infectious diseases, such as pandemic (swine flu) influenza (World Health Organization 2009), Ebola (Green 2014; World Health Organization 2014) and Zika virus (World Health Organization 2016) have been marked by the limits of what can be known ahead of time and the challenges of responding to the particular turnings of outbreaks as they happen. The 2009 pandemic influenza - the topic of research I conducted with colleagues in Australia and Scotland-is a pivotal example of this problem of responding to a pandemic in real time. The 2009 pandemic put huge strain on global, national and local health systems, affecting many individuals and especially pregnant women and people with specific vulnerabilities to respiratory infections. It was a prominent, perhaps dominant, health news story of the period. But the pandemic turned out to be nothing like as severe as it was first thought to be. Moreover, there was insufficient take-up of the HINl vaccine (Bone et al. 2010; Galarce et al. 2011; White et al. 2010; Yi et al. 2011) and it was observed that only minorities or small majorities reported that they intended to, or did, enact recommended social isolation to avoid transmission of the virus (Kiviniemi et al. 2011; Mitchell et al. 2011; Rubin et al. 2009; Van et al. 2010). Like the "swine flu affair" of the 1970s in the United States (Fineberg 2008), the 2009 pandemic raised questions for the public health system of how to shape public action in light of the significant uncertainties which are particular to influenza, and without jeopardizing trust in government and the scientific knowledge on which is built public policy.

Central, too, was immunity, in its medical and social senses. Immunity is not simply an object of biomedicine, it is also deeply entwined with collective life and the interrelations that come with, specifically, contagious diseases. It is also important to recognize that these issues are by no means settled; how individuals conduct themselves in relation to others in time of pandemic is a central and enduring concern for public health systems. In 2009 in the UK, for example, advertisements featured images of travellers on public transport and the following text:

If you could see flu germs, you'd see how quickly they spread. Cold and flu germs can live on some surfaces for hours. Always carry tissues with you and use them to catch your cough or sneeze. Bin the tissue, and to kill the germs, wash your hands with soap and water, or use a sanitiser gel. This is the best way to help slow the spread of flu. Protect yourself and others (NHS Swine Flu Information). 
This advice addresses responsible individuals and asks them to help limit the spread of infection. The final part of the message 'Protect yourself and others' captures the idea that an easily spread influenza virus requires significant cooperation and the internalization of the idea of action on health for the collective good, as well as for oneself. This reference to altruistic action on health indicated that the social response to the 2009 pandemic exemplified biopolitics (Rose 2007). Individuals are expected and encouraged to internalize the idea that they can take action on themselves to sustain and better their health and reproductive futures. This self-subjectification applies to the advice given to members of the general public on the 2009 influenza pandemic. In addition to the advice noted above, individuals were encouraged to arrange a network of "flu friends" who could be called upon in the case of illness, to stay abreast of developments in the media, and adopt expert advice (National Health Service 2009). Publics were also advised to stay home if they suspected they were ill and to contact NHS services online or by telephone and to not attend GP surgeries of $A \& E$, unless instructed to do so. In this view, the communications of 2009 hailed pandemic citizenship fashioned around the imperatives of action to avoid and contain the spread of infection and to make oneself available to expert advice.

In what follows I explore pandemic communications under conditions of uncertainty, as exemplified by the 2009 influenza pandemic and its resonances with other recent contagions. As we will see, uncertainty has the effect of accentuating personalized responses to expert advice. It also sponsors communicative action figured around seeking the "just right" balance of warning and reassurance and related implications for trust in expert knowledge and authority to govern.

\section{The Example of the 2009 Pandemic}

The events of 2009 foregrounded many of the strengths and weaknesses of public health systems across the globe. Key among these was preparedness and capacity to cope with large scale containment strategies which were used to manage the emerging pandemic. The pandemic preparedness plans in place in 2009 required that in the early phases of the pandemic, efforts should be made to sequester infected individuals and to trace their contacts so that the spreading infection could be tracked down and curbed (World Health Organization 2011). Probably a central lesson of 2009 was that such efforts were costly and apparently 
ineffective. In some settings public health professionals were asked to continue this method even when they were aware that the virus was spreading quickly despite their best efforts (Waller et al. 2016).

The 2009 pandemic therefore revealed the importance of being able to quickly assess the biological characteristics and severity of the infection so as to be able to modify the application of resources. Since 2009 , public health systems have attended to the development of evidence-based measures to assess seriousness and the development of local and viable responses to a global pandemic threat (Australian Department of the Prime Minister and Cabinet 2011). Pandemic preparedness, therefore, has demonstrated a marked shift away from uniformity and top-down governance towards local, evidence-based, approaches. For example, Australia's 2009 version of its preparedness plan adopted a traditional method of top-down transmission of expert knowledge and advice to publics. Government in this view was mandated to:

Deliver consistent and accurate public messages nationwide in the event of a pandemic. Governments will make every effort to provide timely and reliable advice to the public, media, businesses and industries. (Australian Department of Health and Ageing 2008: 34)

By 2014, however, the Australian pandemic policy instrument referred to the need for public communications which were "two-way" and "listening" to publics (Australian Department of Health 2014: 63). This approach to feedback on the transmission of information was said to depend on in vivo market research, the monitoring of social media, and a Q\&A website where publics can pose questions and air their opinions (Australian Department of Health 2014: 63). The policy also made reference to the need for specific and tailored messages for vulnerable groups.

However, during 2009 pandemic public communications faced significant challenges, not all of which are obviously addressed in the revised policies and their emphasis on feedback loops, market research and social media. Surveys conducted at the time of the onset of the pandemic in 2009 show that while publics largely endorsed government action on the pandemic, they underestimated risk of infection and only minorities reported that they had adopted recommended behaviours such as social isolation and coughing and sneezing etiquette (Rubin et al. 2009). The findings suggest that individuals interpreted public health advice with 
some scepticism. Research shows also that espoused trust in government was associated with self-reported compliance with public health advice (Lin et al. 2014; Rubin et al. 2009). As noted, populations across the globe adopted vaccination only in small proportions, insufficient to protect the entire population.

This indication of weak public engagement with the pandemic may be explained by a more general effect of risk management. It is surmised that the repetition of warnings over the last few decades-for example, HIV, BSE, Avian Influenza, hospital superbugs, SARS, HINl, Ebola and Zika, to name a few-leads to weariness on the part of publics (Joffe 2011). Diminishment in public engagement with risk is also thought to be an effect of risk society preoccupation with the forecasting and management of risks (Giddens 1998). Public weariness can be thought of as a manufactured risk in the sense that it arises through attempts to manage risk. It is also evident that news on current risks are often framed by established patterns of meaning used to depict previous or contiguous risks (Ungar 2008). It is possible, therefore, that publics have learned to screen out global health alerts and treat media on the topic with a degree of scepticism, a perspective supported by our own (Davis et al. 2014; Davis 2017) and similar research (Hilton and Smith 2010; Holland and Blood 2012). Implied also is that repeated global health alerts coupled with some scepticism on the part of publics may lead them to fall back on personal knowledge and resources.

\section{Public Responses}

The individualization of responses to pandemic risk communications was supported by our own research. Individuals in our interviews and focus groups endorsed expert advice regarding coughing and sneezing etiquette and social isolation, but they did not think that these strategies would be viable in the long run (Davis et al. 2016). Some of our respondents did adopt forms of social isolation, but they also saw in these strategies some flaws and inadequacies. They appeared, in general, to recognize the ease with which infection could occur. For these reasons, many of the people we spoke with resorted to discourse on immunity as a means of coping with a more than likely infection. Almost absent was discourse on personal action as a means of protecting all, apart from among those with severe respiratory illness who were used to dealing with the threat of infection posed by others. Our respondents 
focused on matters such as the building of immunity through consumer products, rest and exercise, and spoke of the need to cultivate and educate their personal immune system, with some reference to childhood experiences of exposure to infection. Individuals seemed to accept that interaction with microbial life was inevitable and important to health and that their immune systems were shaped by their own actions. This "choice immunity" was spoken of as managing one's body and those of dependent others in ways that resonated with the well-known notion of "choice biography" which is said to characterize reflexive modernization (Beck and Beck-Gernsheim 2002).

There are other implications of this resort to choice immunity. Ed Cohen has shown how immunity is a conceptual framing of subjectivity that preceded modern day microbiology (2009). With its root in the Latin munis-also the root for municipal and remuneration, for example-immunity referred to the suspension of one's civic and pecuniary obligation to collective life. Cohen gave examples which include, duty, gift, tax, tribute, sacrifice, and public office (2009). Immunity suspends the "bond of requirement," but also, therefore, reinscribes it (p. 41). It always and necessarily marks the power of the social obligation it refuses, including in matters of health. As Cohen showed, microbiology, and specifically germ theory, appropriated and reconfigured the metaphor of immunity to help narrate the emerging science of cells, microbes and pathogenesis. In particular, the idea of immunity helped to explain how the immune system destroyed cells colonized by alien microbial life and bypassed uninfected cells of the body, although autoimmunity and microchimerism complicate this understanding of biological immunity (Martin 2010). Combined with germ theory, immunity operates to produce a "milieu interieur;" an imaginary of the battle with microbial invaders inside the body (Cohen 2009: 239), a metaphor which accentuates the emphasis on the individual in relation to contagious health threats. Emily Martin has made a similar point that media depictions of immunity have often referred to the war within the body (1994). It is therefore no surprise that individuals resort to the practical and metaphorical properties of immunity when they are asked to contend with the risk of pandemic influenza, which creates uncertainties over which they otherwise have very little apparent control.

These issues are reflected in consumer products, for example, the commercial marketing of probiotic foods and supplements 
(Burges Watson et al. 2009; Koteyko 2009; Nerlich and Koteyko 2008), which address individual consumers in terms of "choice immunity." Probiotics also raise the idea that it is important to replace bacteria that have been killed off due to antibiotic treatment and/or the idea that "good" bacteria will outcompete illness producing bacteria. The scientific underpinning and marketing of probiotics, then, depend on a division of "good" and "friendly" bacteria from disease-producing bacteria.

\section{Be Alert, Not Alarmed}

It is against this backdrop of immunity culture that public health institutions have to shape and circulate messages on how individuals ought to conduct themselves. As with the 2009 pandemic, agencies such as the WHO, regional WHO offices, and lead national public health agencies such as the CDC and Public Health Scotland implement communication strategies and are key sources of expert commentary in worldwide news media.

A central communication challenge is how to shape messages so that they are productive of desired action on the part of members of the general public, when it cannot be known absolutely how matters will transpire. It is clear from our research with public health professionals in Australia and the UK that finding a balance of motivation and reassurance was paramount (Davis et al. 2011, 2013). In this context, public health experts were concerned that publics should be advised and asked to prepare for the pandemic but not in ways that promoted anxiety or promoted panic, as reflected in, for example, runs on supermarkets, pharmacies and clinics. This meant that messages also had to be reassuring but not in a way that led publics to ignore advice, or worse, to become complacent. As Briggs and Nichter have pointed out, pandemic messaging was carefully styled around the notion of "be alert, not alarmed" (2009). They have identified this approach as the "just right" Goldilocks method, that is, the production of alert, but not panicky, reassured, but not complacent publics. For example, in a newspaper article published on 27 April 2009, in the first few days of the pandemic alert, the Chief Health Officer of Australia was quoted to have said:

We should be aware but I'm not overly alarmed at this point. We don't have confirmed cases in Australia but I think there will be some cases in 
the future. We think the population should be alert, should be aware of travellers in their midst who have the flu. But not alarmed at this point, just aware. (Robotham and Pearlman 2009)

In this way, pandemic communications help to constitute the expert-informed, life choices of individuals. Less obvious are obligations to others which also make immunity possible, such as herd immunity and the related practice of altruistic vaccination to protect vulnerable others. It is also important to recognize that explicit reference to immunity is rarely a feature of this public health advice; it is nearly always implied.

\section{“The Boy Who Cried Wolf" \\ and Other Communication Dilemmas}

The 2009 pandemic raised some other problems related to the eventual character of the pandemic as mild for most, but not all. As noted, the 2009 pandemic was quickly found to be less severe than early indications portended, though some groups faced elevated risks and the pattern of morbidity differed from that typical for seasonal influenza (Presanis et al. 2011). It therefore became necessary to manage the communications turn away from alert, but without the cessation of cautionary messaging and continued advice for those who did face higher risk of severe disease. Influenza is known to return, on occasion, in a second wave which has the potential to be more severe for all or some of those affected (Presanis et al. 2011). Uncertainties like these meant that it was imperative to sustain a kind of watchful, just in case, attitude, until such time as an effective vaccine became available. This particular situation of a global alert followed by revisions of preparedness and response and growing evidence of a significantly less dangerous pandemic led to new communications challenges to do with explaining to publics what was happening and how they should therefore conduct themselves. This shifting in messaging across the period of the pandemic implied "the boy who cried wolf" parable (Nerlich and Koteyko 2012), which teaches in narrative form the jeopardy of trust faced by raising a false alarm, too often.

One effect of false alarm is that it may amplify the importance of choice immunity, that is, recourse to the self-reliant management of the body as the means to contend with an uncertain health threat. Sociological perspectives on choice biography point out that under the conditions of neo-liberal economic and political order, individuals are 
forced to rely on themselves and their own decision-making capacities, since there is in the end, nowhere else for them to go (Beck and BeckGernsheim 2002). They nevertheless are bound to depend on expert advice, since no one person can be expert in all the considerations that pertain to health or any other of the major life decisions (Ungar 2003). False alarm destabilizes expert authority and leaves people doubly reliant on themselves. In this view, the tendency for individuals to fall back on their immunity is a rational response to the requirement to take action and because, in the face of the uncertainties which preside in the case of influenza, the body is one apposite arena in which people are able to exercise some control.

Our research shows also that the communication on the pandemic had the potential to divide publics according to their vulnerability, another way in which knowledge and questions played out in the 2009 pandemic. They showed awareness of the "boy who cried wolf" dilemma but also recognized the invidious situation in which public health experts found themselves. They spoke of the needless hype of the media on the pandemic, by which they meant the extent of the reporting on the progress of the pandemic (Davis and Lohm forthcoming). It is important to remember, also, that some groups and individuals were affected and profoundly so, for example, women who were pregnant in 2009. Public communications on the risk of pandemic influenza, therefore, had a schismatic quality in the sense that the mildness of the virus needed to be explained to publics, while some remained at risk. Like the universalism of pandemic preparedness, communications were also faced with the need for nuance and provisionality. This splitting of publics according to their vulnerability (Stephenson et al. 2014), was suggestive also of the coexistence of different modes of pandemic subjectivity. The "not at risk and in general unconcerned" could look upon news media and public communications as needless and hyped, particularly as the pandemic progressed. Vulnerable groups, as we have suggested (Stephenson et al. 2014), at times had trouble recognizing themselves in these messages and once they had established for themselves awareness of their immunological vulnerability, they looked upon the hype as masking what for them was a real and visceral anxiety and set of practical issues of infection control and vaccination. This schism in public engagement accentuates the sense in which people have to make up their own mind on how to act in the context of what our vulnerable interviewees suggested were confusing, mixed messages. 


\section{Conclusion}

The communications challenges of emerging, changing pandemics are considerable. Messages have to, at first, inform publics without frightening them, but also reassure them without producing complacency. As the example of the 2009 pandemic indicates, as the infection progressed and evidence emerged of the health effects of the $\mathrm{HINl}$ virus, public health systems had to explain that the pandemic was mild, though this situation could change. They also had to embed in this more general message information for minorities that they remained at serious risk. This changing, complex message risked provoking accusations of false alarm and therefore mistrust, as has happened in previous outbreak situations (Fineberg 2008). As I argued, too, the mixing of a general message of a mild pandemic which might change with messages that also some particular kinds of people were at risk, placed vulnerable people in the difficult situation of having to identify themselves in these messages and take action when others were sceptical and unlikely to be acting to protect themselves and those around them.

When we asked people in our research to talk about HINl and specifically if it could be prevented, people acknowledged that infection was unlikely to be avoided and, accordingly, they were forced to reflect on the capacity of their body to cope with infection. As indicated, this resort to personal immunity was not quite the same as the science of cellular immunity discussed by Cohen and others. It more closely resembled an acceptance of the possibility of the presence of the virus in the body and fashions an arena for volitional action on the body when other forms of action seem to have less practical value, as was the case in 2009. For example, social isolation and possibly vaccination, were endorsed but by and large not extensively taken up, particularly given that the virus was in general mild and easy to catch.

Because the HINl virus was observed to be so easily transmitted, the resort to personal immunity had doubled value. It may be for this reason that publics endorsed expert advice to self-isolate and vaccinate, but did not do so, that is, they fended for themselves and the pandemic turned into a mild one, anyway, though not for everyone. Appeals to the collective good and altruistic vaccination on which depend public health efforts concerning pandemics, may miss the point that individuals are led to think of their personal immunity as an arena within which they can sustain themselves in the face of deeply uncertain threats which arise in 
communal life. If as Cohen has suggested, immunity is fused with ideas of cellular action on microbial pathogens but it is also a metaphor for freedom from obligation. It seems, then, that a key lesson from 2009 was that freedom from the dangers of infection found in personal action on immunity also implied freedom from having to act in the interest of others; the more free one is from the dangers of infection-the stronger one's immunity - the less one needs to consider the dangers which others face, particularly under conditions of uncertainty. Individualized ideas of immunity in connection with uncertainties may limit the effectiveness of public health communications on influenza pandemics and other contagious threats.

Acknowledgements This chapter is based on research funded by an Australian Research Council Discovery Project grant on pandemic influenza (DP110101081). I would like to acknowledge the assistance of my colleagues from the pandemic influenza project, Niamh Stephenson, Paul Flowers, Emily Waller, Casimir MacGregor and Davina Lohm. I am also very grateful for the time and efforts of those who participated in the interviews and focus groups for the research.

\section{REFERENCES}

Australian Department of Health. 2014. Australian Health Management Plan for Pandemic Influenza. Canberra: Commonwealth of Australia.

Australian Department of Health and Ageing. 2008. Australian Health Management Plan for Pandemic Influenza: Important Information for all Australians. Canberra: Australian Government, Department of Health and Ageing.

Australian Department of the Prime Minister and Cabinet. 2011. National Action Plan for Human Influenza Pandemic. Canberra: Commonwealth of Australia.

Beck, Ulrich, and Elisabeth Beck-Gernsheim. 2002. Individualisation: Institutionalised Individualism and Its Social and Political Consequences. London: Sage.

Bone, A., J. Guthmann, J. Nicolau, and D. Levy-Bruhl. 2010. Population and Risk Group Uptake of HINl Influenza Vaccine in Mainland France 2009-2010: Results of a National Vaccination Campaign. Vaccine 28 (51): 8157-8161.

Briggs, C., and M. Nichter. 2009. Biocommunicability and the Biopolitics of Pandemic Threats. Medical Anthropology 28 (3): 189-198. 
Burges Watson, D., T. Moreira, and M. Murtagh. 2009. Little Bottles and the Promise of Probiotics. Health 13 (2): 219-234. https://doi. org/10.1177/1363459308099685.

Cohen, E. 2009. A Body Worth Defending: Immunity, Biopolitics and the Apotheosis of the Modern Body. Durham: Duke University Press.

Davis, M. 2017. 'Is It Going to be Real?' Narrative and Media on a Pandemic. Forum Qualitative Sozialforschung/Forum: Qualitative Social Research 18 (1). Online: http://nbn-resolving.de/urn:nbn:de:0114-fqs1701187.

Davis, M., and D. Lohm. Forthcoming. Pandemics, Publics and Narrative. New York: Oxford University Press.

Davis, M., P. Flowers, and N. Stephenson. 2013. 'We Had to Do What We Thought Was Right at the Time': Retrospective Discourse on the 2009 HINl Pandemic in the UK. Sociology of Health \& Illness 36 (3): 369-382.

Davis, M., N. Stephenson, and P. Flowers. 2011. Compliant, Complacent or Panicked? Investigating the Problematisation of the Australian General Public in Pandemic Influenza Control. Social Science \& Medicine 72 (6): 912-918.

Davis, M., P. Flowers, D. Lohm, E. Waller, and N. Stephenson. 2014. 'We Became Sceptics': Fear and Media Hype in General Public Narrative on the Advent of Pandemic Influenza. Sociological Inquiry 84 (3): 499-518.

Davis, M., P. Flowers, D. Lohm, E. Waller, and N. Stephenson. 2016. Immunity, Biopolitics and Pandemics: Public and Individual Responses to the Threat to Life. Body \& Society 22 (4): 130-154.

Fineberg, H. 2008. Preparing for Avian Influenza: Lessons from the 'Swine Flu Affiar'. The Journal of Infectious Diseases 197 (1): S14-S18.

Galarce, E., S. Minsky, and K. Viswanath. 2011. Socioeconomic Status, Demographics, Beliefs and $\mathrm{A}(\mathrm{H} 1 \mathrm{Nl})$ Vaccine Uptake in the United States. Vaccine 29 (32): 5284-5289.

Giddens, A. 1998. Risk Society: The Context of British Politics. In The Politics of Risk Society, ed. J. Franklin. Cambridge: Polity.

Green, A. 2014. West Africa Struggles to Contain Ebola Outbreak. The Lancet 383, 5 April.

Hilton, S., and E. Smith. 2010. Public Views of the UK Media and Government Reaction to the 2009 Swine Flu Pandemic. BMC Public Health 10: 697.

Holland, K., and W. Blood. 2012. Public Responses and Reflexivity During the Swine Flu Pandemic in Australia. Journalism Studies iFirst. https://doi.org/1 $0.1080 / 1461670 X .2012 .744552$.

Joffe, H. 2011. Public Apprehension of Emerging Infectious Diseases: Are Changes Afoot? Public Understanding of Science 20 (4): 446-460.

Kiviniemi, M., P. Ram, L. Kozlowski, and K. Smith. 2011. Perceptions of and Willingness to Engage in Public Health Precautions to Prevent $2009 \mathrm{H} 1 \mathrm{Nl}$ Influenza Transmission. BMC Public Health 11 (1): 152. https://doi.org/ 10.1186/1471-2458-11-152. 
Koteyko, N. 2009. 'I Am a Very Happy, Lucky Lady, and I Am Full of Vitality!' Analysis of Promotional Strategies on the Websites of Probiotic Yoghurt Producers. Critical Discourse Studies 6 (2): 111-125.

Lin, L., E. Savoia, F. Agboola, and K. Viswanath. 2014. What Have We Learned About Communication Inequalities During the HINl Pandemic: A Systematic Review of the Literature. BMC Public Health 14 (1): 484. https://doi.org/10.1186/1471-2458-14-484.

Martin, E. 1994. Flexible Bodies: Tracking Immunity in American Culture from the Days of Polio to the Age of AIDS. Boston: Beacon Press.

Martin, A. 2010. Microchimerism in the Mother(land): Blurring the Borders of Body and Nation. Body \& Society 16 (3): 23-50.

Mitchell, T., D.L. Dee, C.R. Phares, et al. 2011. Non-Pharmaceutical Interventions During an Outbreak of 2009 Pandemic Influenza A (H1N1) Virus Infection at a Large Public University, April-May 2009. Clinical Infectious Diseases 52 (1): S138-S145.

National Health Service. 2009. Important Information About Swine Flu. Edited by Wales National Health Services for England, Scotland and Northern Ireland.

Nerlich, B., and N. Koteyko. 2008. Balancing Food Risks and Food Benefits: The Coverage of Probiotics in the UK National Press. Sociological Research Online $13(3)$ : 1 .

Nerlich, B., and N. Koteyko. 2012. Crying Wolf? Biosecurity and Metacommunication in the Context of the 2009 Swine Flu Pandemic. Health of Place 18 (4): 710-717. https://doi.org/10.1016/j.healthplace.2011.02.008.

Presanis, A., R. Pebody, B. Paterson, B. Tom, P. Birrell, A. Charlett, and M. Lipsitch. 2011. Changes in Severity of 2009 Pandemic A/H1Nl Influenza in England: A Bayesian Evidence Synthesis. BMJ 343: d5408. https://doi.org/10.1136/bmj.d5408.

Robotham, Julie and Jonathan Pearlman. 2009. Global Alarm as Killer Swine Flu Spreads. The Sydney Morning Herald, 27 April. Online: http://www.smh. com.au/world/global-alarm-as-killer-swine-flu-spreads-20090426-ajjo.html.

Rose, N. 2007. The Politics of Life Itself: Biomedicine, Power and Subjectivity in the Twenty-First Century. Princeton: Princeton University Press.

Rubin, G., R. Amlot, L. Page, and S. Wessely. 2009. Public Perceptions, Anxiety, and Behaviour Change in Relation to the Swine Flu Outbreak: Cross Sectional Telephone Survey. British Medical Journal 339 (Online First).

Stephenson, N., M. Davis, P. Flowers, E. Waller, and C. MacGregor. 2014. Mobilising 'Vulnerability' in the Public Health Response to Pandemic Influenza. Social Science and Medicine 102: 10-17.

Ungar, S. 2003. Misplaced Metaphor: A Critical Analysis of the 'Knowledge Society'. Canadian Review of Sociology 40 (3): 331-347.

Ungar, Sheldon. 2008. Global Bird Flu Communication: Hot Crisis and Media Reassurance. Science Communication 29 (4): 472-497. 
Van, D., M. McLaws, J. Crimmins, R. MacIntyre, and H. Seale. 2010. University Life and Pandemic Influenza: Attitudes and Intended Behaviour of Staff and Students towards Pandemic (H1Nl) 2009. BMC Public Health 10 (1): 130. https://doi.org/10.1186/1471-2458-10-130.

Waller, E., M. Davis, and N. Stephenson. 2016. Australia's Pandemic Influenza 'Protect' Phase: Emerging Out of the Fog of Pandemic. Critical Public Health 26 (1): 99-113.

White, S., R. Petersen, and J. Quinlivan. 2010. Pandemic (H1Nl) 2009 Influenza Vaccine Uptake in Pregnant Women Entering the 2010 Influenza Season in Western Australia. MJA 193: 405-407.

World Health Organization. 2009. WHO, 2009 World Now at the Start of 2009 Influenza Pandemic. Online: http://www.who.int/mediacentre/news/statements/2009/hlnl_pandemic_phase6_20090611/en/index.html.

World Health Organization. 2011. Implementation of the International Health Regulations (2005). Report of the Review Committee on the Functioning of the International Health Regulations (2005) in Relation to Pandemic (HlNl) 2009. Report by the Director-General. Geneva: World Health Organisation.

World Health Organization. 2014. Statement on the 1st Meeting of the IHR Emergency Committee on the 2014 Ebola Outbreak in West Africa. Online: http://www.who.int/mediacentre/news/statements/2014/ ebola-20140808/en/.

World Health Organization. 2016. Fifth Meeting of the Emergency Committee Under the International Health Regulations (2005) Regarding Microcephaly, Other Neurological Disorders and Zika Virus. http://www.who.int/ mediacentre/news/statements/2016/zika-fifth-ec/en/.

Yi, S., D. Nonaka, M. Nomoto, J. Kobayashi, and T. Mizue. 2011. Predictors of the Uptake of A (H1Nl) Influenza Vaccine: Findings from a PopulationBased Longitudinal Study in Tokyo. PLoS ONE 6 (4): e18893. 